This item was submitted to Loughborough's Research Repository by the author.

Items in Figshare are protected by copyright, with all rights reserved, unless otherwise indicated.

\title{
A novel automated bioreactor for scalable process optimisation of haematopoietic stem cell culture
}

PLEASE CITE THE PUBLISHED VERSION

http://dx.doi.org/10.1016/j.jbiotec.2012.06.025

PUBLISHER

(C) Elsevier B.V.

VERSION

AM (Accepted Manuscript)

LICENCE

CC BY-NC-ND 4.0

\section{REPOSITORY RECORD}

Ratcliffe, Elizabeth, Katie E. Glen, Victoria L. Workman, Adrian J. Stacey, and Robert James Thomas. 2019. "A Novel Automated Bioreactor for Scalable Process Optimisation of Haematopoietic Stem Cell Culture". figshare. https://hdl.handle.net/2134/13177. 
This item was submitted to Loughborough's Institutional Repository (https://dspace.lboro.ac.uk/) by the author and is made available under the following Creative Commons Licence conditions.

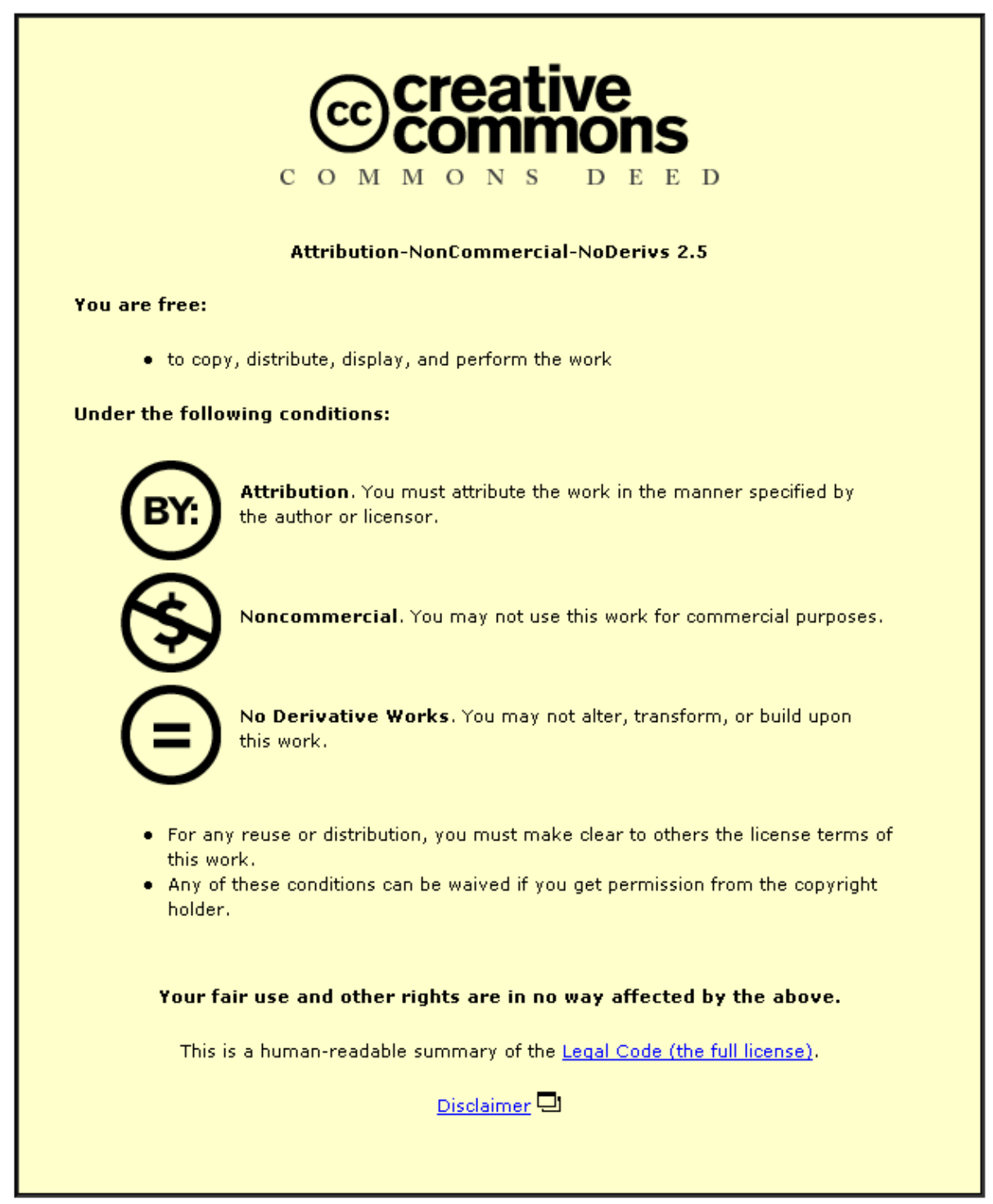

For the full text of this licence, please go to: http://creativecommons.org/licenses/by-nc-nd/2.5/ 
Short communication

\title{
A Novel Automated Bioreactor for Scalable Process Optimisation of Haematopoietic Stem Cell Culture
}

\author{
E. Ratcliffe ${ }^{\mathrm{a}}$, K.E.Glen ${ }^{\mathrm{a}}$, V.L.Workman ${ }^{\mathrm{a}}$, A.J. Stacey ${ }^{\mathrm{b}}$, R.J. Thomas ${ }^{\mathrm{a} *}$

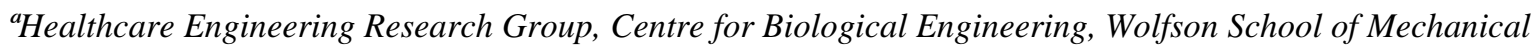 \\ and Manufacturing Engineering, Loughborough University, Loughborough, Leicestershire, LE11 3TU, United \\ Kingdom. \\ ${ }^{b}$ TAP Biosystems, York Way, Royston, Hertfordshire, SG8 5WY, United Kingdom.

\begin{abstract}
*Corresponding author: R.J. Thomas, Healthcare Engineering Research Group, Centre for Biological Engineering, Wolfson School of Mechanical and Manufacturing Engineering, Loughborough University, Loughborough, LE11 3TU, United Kingdom. Telephone: +44-1509-227601, Fax: +44-1509-564894, E-mail address: R.J.Thomas@lboro.ac.uk
\end{abstract}

\begin{abstract}
Proliferation and differentiation of haematopoietic stem cells (HSCs) from umbilical cord blood at large scale will potentially underpin production of a number of therapeutic cellular products in development, including erythrocytes and platelets. However, to achieve production processes that are scalable and optimised for cost and quality, scaled down development platforms that can define process parameter tolerances and consequent manufacturing controls are essential.

We have demonstrated the potential of a new, automated, $24 \times 15 \mathrm{~mL}$ replicate suspension bioreactor system, with online monitoring and control, to develop an HSC proliferation and differentiation process for erythroid committed cells $\left(\mathrm{CD} 71^{+}, \mathrm{CD} 235 \mathrm{a}^{+}\right)$. Cell proliferation was relatively robust to cell density and oxygen levels and reached up to 6 population doublings over 10 days. The maximum suspension culture density for a 48 hour total media exchange protocol was established to be in the order of $10^{7}$ cells $/ \mathrm{mL}$. This system will be valuable for the further HSC suspension culture cost reduction and optimisation necessary before the application of conventional stirred tank technology to scaled manufacture of HSC derived products.
\end{abstract}

Keywords: Haematopoietic stem cells, Suspension culture, Bioreactor, Cell culture automation, Process development.

Abbreviations: HSCs, haematopoietic stem cells; $\operatorname{ambr}^{\mathrm{TM}}$, advanced microscale bioreactor; rpm, revolutions per minute; $\mu$, mean; SEM, standard error of the mean; FITC, Fluorescein isothiocyanate; $\mathrm{dO}_{2}$, dissolved oxygen; ANOVA, analysis of variance; SCF, stem cell factor; IGF-1, insulin-like growth factor 1; IL-3, interleukin 3; EPO, erythropoietin. 


\section{Introduction}

Haematopoietic stem cells (HSCs) are multipotent cells with the ability to self-renew and differentiate into all blood cell lineages (Nielsen, 1999; Rizo et al., 2006). These properties confer a wide range of possible therapeutic applications for which umbilical cord blood constitutes a readily available cell source (Neildez-Nguyen et al., 2002). The development of such HSC-based products, i.e. red blood cells, has made significant progress in recent years (Douay and Andreu, 2007; Fujimi et al., 2008; Giarratana et al., 2005; Miharada et al., 2006). However, the number of cells required for a therapeutic dose will be up to the order of $10^{12}$ cells per patient, necessitating a cell expansion process that sets a formidable production scale challenge for conventional bioprocessing formats. Intensification of commonly used static expansion systems (e.g. T-flasks, gas-permeable bags) is inherently limited by nutrient and gas concentration gradients, and a lack of on-line monitoring and control of key environmental conditions, limiting maximum supportable cell density (Liu et al., 2006). Understanding the feasibility of a scale-up approach in conventional stirred tank systems requires the use of low volume systems for economic process design, development and optimisation, whilst retaining relevance to downstream manufacturing bioprocesses (Kirouac and Zandstra, 2008; Ratcliffe et al., 2011).

Cell culture of HSCs to erythroid cells is currently costly, and scaled down processes are required for optimisation and cost reduction prior to scale up. Here we show the proliferation and erythroid commitment of HSCs at the lowest (and therefore most cost effective) suspension scale yet reported using an automated process development platform (the advanced microscale bioreactor workstation (ambr ${ }^{\mathrm{TM}}$ ), TAP Biosystems, Royston, UK) (Fig. 1). The ability of this system to predict operating conditions at scale was recently demonstrated in terms of both cell productivity/growth and the physicochemical environment (Hsu et al., 2012). We show that ambr ${ }^{\mathrm{TM}}$ culture offers the control required to detect different cell responses to operating parameters, such as $\mathrm{O}_{2}$ tension and seeding density, and can support high density cell culture of HSCs. It will therefore form a valuable tool for optimisation and cost reduction of a complex and costly culture system prior to scale up.

\section{Brief Methods}

Frozen CD34 ${ }^{+}$enriched umbilical cord blood cells (negative selection using RoboSep ${ }^{\circledR}$ automated cell separator, Stem Cell Technologies, Grenoble, France) were provided courtesy of Celgene Cellular Therapeutics (New Jersey, USA) after proliferation for 7 days in 2D culture conditions using StemSpan SFEM (serum-free expansion medium) (09650, StemCell Technologies) supplemented with the following cytokines and reagents for erythroid cell proliferation and differentiation; 100ng/mL SCF, 40ng/mL IGF-1, 5ng/mL IL-3, 3IU/mL EPO (R\&D Systems, Oxford, UK), 40 $\mu \mathrm{g} / \mathrm{mL}$ Lipid and $1 \mu \mathrm{M}$ Dexamethasone (SigmaAldrich, Poole, UK). Prior to cell defrost, $\mathrm{ambr}^{\mathrm{TM}}$ vessels were loaded with $14 \mathrm{~mL}$ of this medium and stabilised at $37^{\circ} \mathrm{C}$, experimental $\mathrm{dO}_{2}$ level, and $\mathrm{pH}$ 7.4. Automated antifoam additions $(20 \mu \mathrm{L}$ of $1 \%$ solution, Sigma-Aldrich) were made every $48 \mathrm{~h}$, or as required. Automated sodium bicarbonate additions $(20 \mu \mathrm{L}$ of $1 \mathrm{M}$ solution, Sigma-Aldrich) maintained cultures at pH7.4 (trigger pH7.2, monitored every 2h). Cultures were initiated at several cell 
seeding densities as stated in the results tables (viability $96.27 \% \pm 1.12 \%(\mu \pm \mathrm{SEM})$ ). Cultures were sampled for cell counting (Countess automated cell counter, Invitrogen, Paisley, UK) and metabolite analysis (Nova Bio-Profile Flex, Nova Biomedical, Runcorn, UK). Replacement of culture medium was conducted through centrifugation and resuspension of cells in fresh medium at intervals stated in results. Flow cytometry for erythroid lineage markers was performed after each expansion using CD235a-FITC or CD71FITC (BD Biosciences, Oxford, UK) conjugated antibodies and appropriate isotype controls according to manufacturer's instructions. A Cell Lab Quanta SC Flow Cytometer (Beckman Coulter, High Wycombe, UK) was used for analysis. Experimental runs were performed in triplicate, results expressed as the mean value of the data \pm standard error of the mean $(\mu \pm$ SEM). Significance was determined using ANOVA (Minitab).

\section{Results and Discussion}

In order to determine feasibility of HSC proliferation in $\mathrm{ambr}^{\mathrm{TM}}$, to identify conditions for rapid cell proliferation, and to establish time to the primary media exchange, cells were cultured under different oxygen tensions $\left(\mathrm{dO}_{2} 5 \%, 15 \%\right)$ and cell densities $\left(2 \times 10^{4} / \mathrm{mL}\right.$, $8 \times 10^{4} / \mathrm{mL}$ ). Slower proliferation observed after 5 days ( $5 \mathrm{~d}$ ) in all cultures indicated that the first media exchange should occur within this period. Both $\mathrm{dO}_{2}$ and cell density had a statistically significant effect on proliferation at $5 \mathrm{~d}(\mathrm{P} \leq 0.002)$, and there was a statistically significant interaction between the two parameters $(\mathrm{P}<0.001)$. Highest proliferation was achieved with $8 \times 10^{4}$ cells $/ \mathrm{mL}$ seeding density and $15 \% \mathrm{dO}_{2}(\operatorname{Exp} 1$, Table 1). A further culture was conducted with total media exchange after 4 days, and every 2 days thereafter, to further optimise around these identified operating parameters (Seeding density $4 \times 10^{4}, 8 \times 10^{4}$, $\left.1.2 \times 10^{5} / \mathrm{mL} ; \mathrm{dO}_{2} 7.5 \%, 15 \%, 21 \%\right)$. Lower seeding density increased proliferation after 8 days culture $(\mathrm{P}<0.01)$ whilst $\mathrm{O}_{2}$ in this range was no longer significant (Exp 2, Table 1). The best growth conditions were continued to 10d (shown in bold) and achieved over 6 population doublings (all growth curves shown in Figure 2). In order to establish the potential of the bioreactor to develop reduced cost processing strategies, complete medium replacement, 50\% medium dilution, and cytokine addition without medium dilution were trialled. No significant differences in proliferation were observed after 6 days (3.16, 3.27, 2.86 PDs respectively), but a small significant proliferative advantage was observed after 8 days (4.4, 3.9, 3.7 PDs respectively). All data from experiment 2 was used to calculate coefficient of variation of $12.5 \%$ for replicate vessels indicating system robustness across the experimental range. At the end of all experiments the cells strongly expressed markers CD71 (79-84\%) and CD235a (51-64\%) characteristic of erythroid lineage development and had viability of $90-97 \%$, with no statistically significant differences between conditions. Cells processed in ambr ${ }^{\mathrm{TM}}$ were also capable of producing BFU-E colonies indicative of erythroid commitment (inset Figure 2).

In order to establish the maximum supported cell density for a 48h media exchange suspension process, and therefore the most efficient production density range, HSCs were cultured without cell dilution. Over four successive cultures cells achieved densities of 0.98$1.37 \times 10^{7}$ cells $/ \mathrm{mL}$. This was not dependent on the initial cell density $\left(4 \times 10^{4}-1.2 \times 10^{6} / \mathrm{mL}\right)$ indicating a density limit rather than an intrinsic cell proliferative limit. In order to determine 
if cytokine concentrations or reactor stir rates were limiting cell density these were both increased throughout culture (up to 3-fold and 1000rpm respectively). This had no significant effect on the terminal density and did not adversely affect viability. Nutrient consumption, metabolite production, $\mathrm{pH}$, and $\mathrm{dO}_{2}$, were monitored during the culture to identify candidates for cell density limitations. $\mathrm{pH}$ and $\mathrm{dO}_{2}$ set levels did not deviate, indicating these factors are unlikely to limit cell density or growth at currently observed levels. As shown inset in Figure 3 , the dominant ammonia source was not related to cell culture density; pre-passage cell concentration increased by more than an order of magnitude, but the ammonia concentration range remained comparable and is therefore also unlikely to be the limiting factor for cell density at the levels observed.

Glucose consumption per cell was calculated to identify required feed rates. Average early consumption rate $(0.0166 \mathrm{ng} / \mathrm{cell} / \mathrm{h}$, range $0.007-0.025 \mathrm{ng} / \mathrm{cell} / \mathrm{h}$, calculated from first 4 hours of culture at day 6 in all experimental conditions) indicated complete depletion would occur in approximately 24 hours at a density at the order of $10^{7}$ cells $/ \mathrm{mL}$ assuming constant metabolic activity per cell. However, glucose (and glutamine) concentrations in high density culture did not reduce beneath $3.6 \mathrm{~g} / \mathrm{L}$ (and $2.5 \mathrm{mmol}$ ) from fresh media levels of $4.5 \mathrm{~g} / \mathrm{L}$ (and $4 \mathrm{mmol}$ ). This indicates a substantial change in glucose consumption through the culture period and a requirement for more extensive metabolic studies. Lactate concentration in culture was usually beneath the limits of detection. However, it was measured at 0.1 to $1 \mathrm{~g} / \mathrm{L}$ in some of the higher density cultures (all $>1 \times 10^{6}$ cells $/ \mathrm{mL}$ ) but showed no relationship to cell density beyond this. This lack of relationship indicates that lactate production per cell is highly variable at different points in culture. Lactate has been reported inhibitory to cell growth at the concentrations observed so it could be a factor in the reduced proliferation at higher densities or at the density limit (Hassell et al., 1991).

\section{Conclusion}

HSCs are good candidates for suspension culture production systems as many of the relevant cell types are naturally non-adherent. This should facilitate their clinical production due to the easy availability of large biopharmaceutical suspension bioreactors. The data reported here shows that HSCs can be cultured in the ambr ${ }^{\mathrm{TM}}$ platform at $10 \mathrm{~mL}$ suspension scale, the lowest yet reported, and this can generate useful data for analysing parameters influencing cell growth, critical for necessary cost reduction studies. Metabolic data indicates that achieving densities in excess of those reported will be likely to require a perfused approach to cell produced factor removal and nutrient supply. This scaled down system of stirred tank operation can successfully support HSC proliferation and differentiation and therefore provide a valuable tool for further exploring the limits of HSC bioprocessing.

\section{Acknowledgements}

This work was funded by Celgene Cellular Therapeutics via the US Defense Advanced Research Projects Agency (DARPA) and the Defense Sciences Office (DSO) Blood Pharming programme (Grant number FA9550-08-1-0392). 


\section{References}

Douay, L., Andreu, G., 2007. Ex vivo production of human red blood cells from hematopoietic stem cells: what is the future in transfusion? Transfus. Med. Rev. 21 (2), 91100.

Fujimi, A., Matsunaga, T., Kobune, M., Kawano, Y., Nagaya, T., Tanaka, I., Iyama, S., Hayashi, T., Sato, T., Miyanishi, K., Sagawa, T., Sato, Y., Takimoto, R., Takayama, T., Kato, J., Gasa, S., Sakai, H., Tsuchida, E., Ikebuchi, K., Hamada H., Niitsu, Y., 2008. Ex vivo large-scale generation of human red blood cells from cord blood CD34+ cells by co-culturing with macrophages. Int. J. Hematol. 87, 339-350.

Giarratana, M-C., Kobari, L., Lapillonne, H., Chalmers, D., Kiger, L., Cynober, T., Marden, M., Wajcman, H., Douay, L., 2005. Ex vivo generation of fully mature human red blood cells from hematopoietic stem cells. Nat. Biotechnol. 23 (1), 69-74.

Hassell, T., Gleave, S., Butler M., 1991. Growth inhibition in animal cell culture. The effect of lactate and ammonia. Appl Biochem Biotechnol. 30, 29-41.

Hsu, W., Aulakh, R., Traul, D., Yuk, I., 2012. Advanced microscale bioreactor system: a representative scale-down model for bench-top bioreactors. Cytotechnology. Online first EPub. DOI 10.1007/s10616-012-9446-1

Kirouac, D., Zandstra, P., 2008. The systematic production of cells for cell therapies. Cell Stem Cell 3, 369-381.

Liu, Y., Liu, T., Fan, X., Ma, X., Cui, Z., 2006. Ex vivo expansion of hematopoietic stem cells derived from umbilical cord blood in rotating wall vessel. J. Biotechnol. 124, 592-601.

Miharada, K., Hiroyama, T., Sudo, K., Nagasawa, T., Nakamura, Y., 2006. Efficient enucleation of erythroblasts differentiated in vitro from hematopoietic stem and progenitor cells. Nat. Biotechnol. 24 (10), 1255-1256.

Neildez-Nguyen, T., Wajcman, H., Marden, M. C., Bensidhoum, M., Moncollin, V., Giarratana, M-C., Kobari, L., Thierry, D., Douay, L., 2002. Human erythroid cells produced ex vivo at large scale differentiate into red blood cells in vivo. Nat. Biotechnol. 20, 467-472.

Nielsen, L. K., 1999. Bioreactors for hematopoietic cell culture. Annu. Rev. Biomed. Eng. 1, 129-152.

Ratcliffe, E., Thomas, R. J., Williams, D. J., 2011 Current understanding and challenges in bioprocessing of stem cell-based therapies for regenerative medicine. Brit. Med. Bull. 100, 137-155.

Rizo, A., Vellenga, E., de Haan, G., Schuringa, J. J., 2006. Signalling pathways in selfrenewing hematopoietic and leukemic stem cells: do all stem cells need a niche? Hum. Mol. Genet. 15, R210-219. 
Table 1 The average population doublings achieved under several seeding density and oxygen tension culture conditions in $\operatorname{ambr}^{\mathrm{TM}}$ ( $\mu \pm \mathrm{SEM}$ of triplicate cultures) identify the levels at which these parameters support rapid cell growth.

\begin{tabular}{cccccc} 
Experiment/Culture & Cell Density / & \multicolumn{4}{c}{ Population Doublings @ $\mathrm{dO}_{2}$} \\
\cline { 3 - 6 } duration & $\mathrm{mL}$ & $\mathrm{dO}_{2} 5 \%$ & $\mathrm{dO}_{2} 7.5 \%$ & $\mathrm{dO}_{2} 15 \%$ & $\mathrm{dO}_{2} 21 \%$ \\
\hline Exp 1: $5 \mathrm{~d}$ & $2 \times 10^{4}$ & $2.29 \pm 0.10$ & & $2.09 \pm 0.21$ & \\
& $8 \times 10^{4}$ & $2.24 \pm 0.10$ & & $3.76 \pm 0.16$ & \\
\hline Exp 2: $8 \mathrm{~d}$ & $4 \times 10^{4}$ & & $\mathbf{4 . 9 8} \pm \mathbf{0 . 0 7}$ & $\mathbf{4 . 9 7} \pm \mathbf{0 . 5 4}$ & $4.43 \pm 0.40$ \\
& $8 \times 10^{4}$ & & & $4.36 \pm 0.02$ & $4.10 \pm 0.16$ \\
& $1.2 \times 10^{5}$ & & $4.11 \pm 0.02$ & $3.91 \pm 0.07$ & $4.30 \pm 0.22$ \\
\hline Exp 2: $10 \mathrm{~d}$ & $4 \times 10^{4}$ & & $\mathbf{6 . 3 1} \pm \mathbf{0 . 0 9}$ & $\mathbf{6 . 0 5} \pm \mathbf{0 . 2 3}$ &
\end{tabular}


Fig. 1. The ambr ${ }^{\mathrm{TM}}$ automated suspension culture process development workstation: (1) Liquid handler, (2) Culture vessel control stations, (3) Pipette racks, (4) Reagent and sample plates. Culture vessel inset: (5) Vessel cap, (6) Gas supply filter, (7) Gas sparge tube, (8) Impeller, (9) pH sensor, (10) $\mathrm{dO}_{2}$ sensor. The workstation comprises 24 independent suspension culture bioreactors and offers precise control of the culture environment through online monitoring and automated control of temperature, $\mathrm{pH}$, gassing, stirring, cell density and liquid handling.

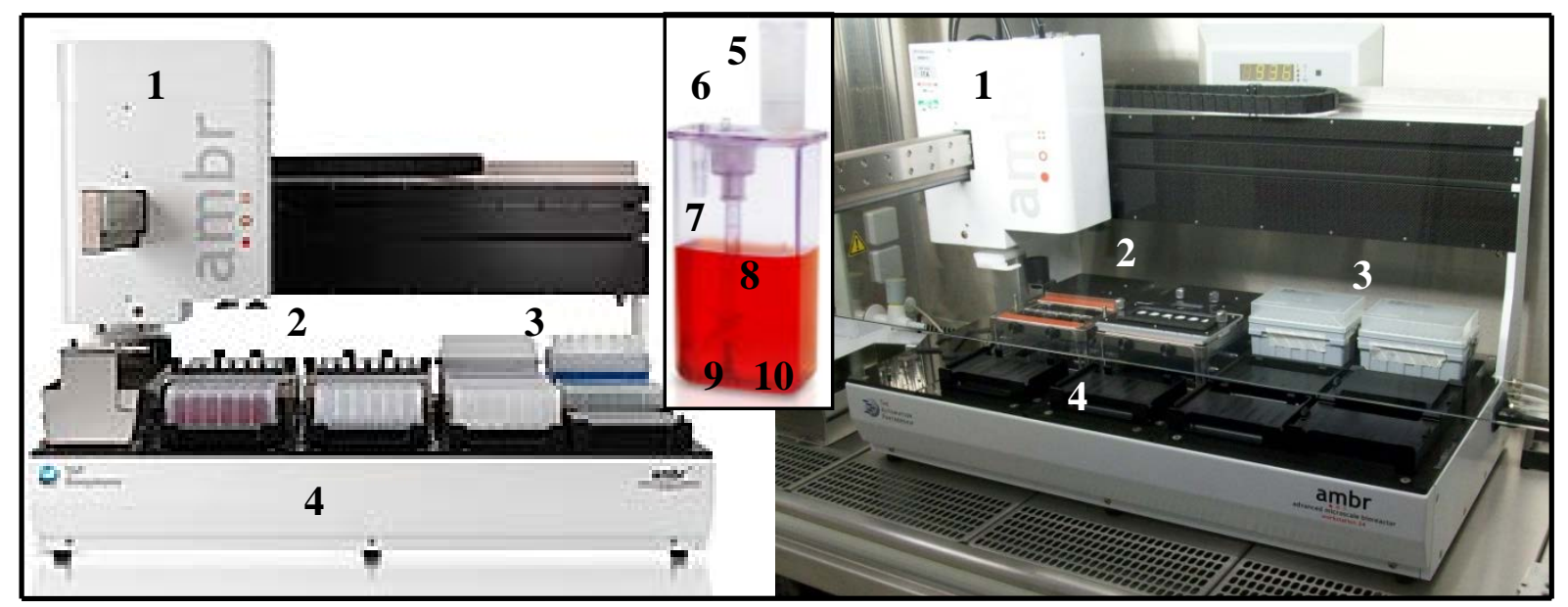


Figure 2 Growth curves for variable cell seeding density (SD) and oxygen tension $\left(\mathrm{O}_{2}\right)$ culture in $\mathrm{ambr}^{\mathrm{TM}}$. Cells were cultured under the conditions described in Table 1 (Exp 2, 8 days); Density: Low $=4 \times 10^{4} / \mathrm{mL}$, Mid $=8 \times 10^{4} / \mathrm{mL}$, High $=1.2 \times 10^{5} / \mathrm{mL} ; \mathrm{dO}_{2}$ : Low $=7.5 \%$, Mid $=15 \%$, High $=21 \%$. Inset graphs; cells express CD235a and CD71 after proliferation, indicators of erythroid lineage development, as shown by these typical flow cytometry profiles. Cells from the bioreactor also produced typical BFU-E colonies (inset) confirming erythroid lineage.

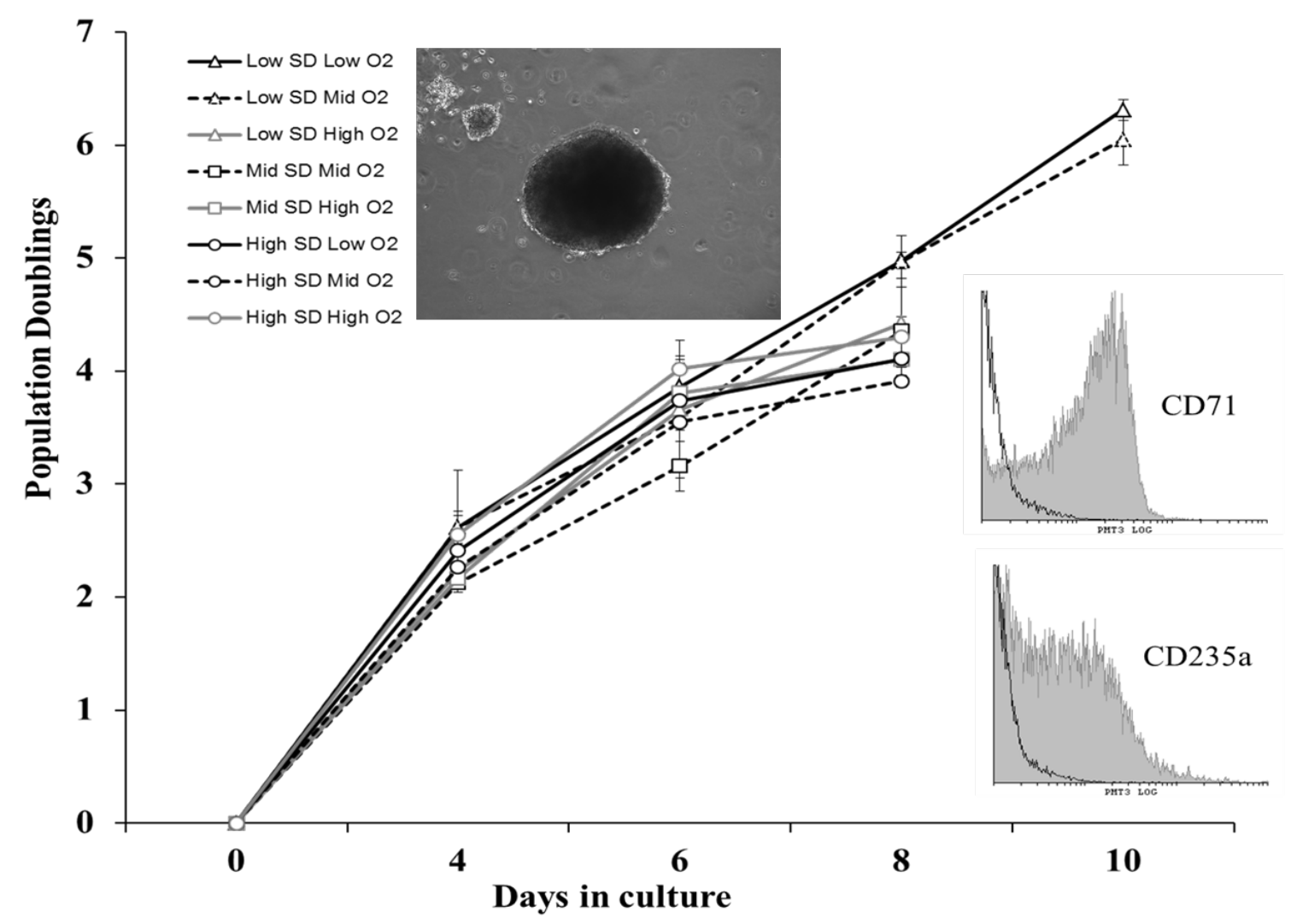


Figure 3 Growth curves for HSC culture to high density in $\operatorname{ambr}^{\mathrm{TM}}$ without cell dilution. Cells were cultured under various conditions to high density. Start and End cell density of each culture are annotated. All conditions progressively increase to 3 fold normal cytokine supplementation and $1000 \mathrm{rpm}$ stir rates. Higher seeding densities reduce growth rates but do not alter terminal density. The inset graph shows a lack of strong correlation between cell density and ammonia concentration (in this range) measured at the end of each culture period.

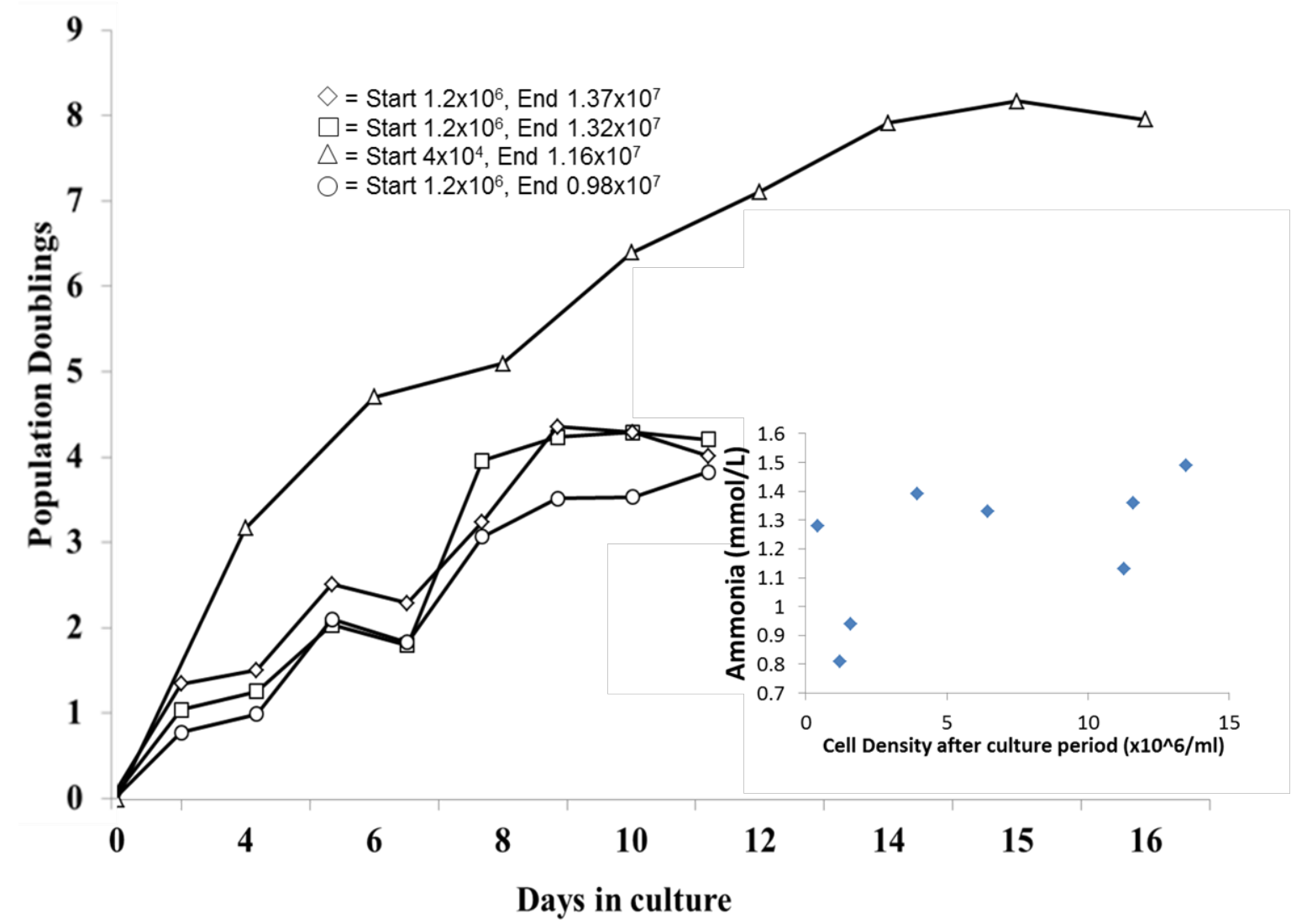

